\title{
A PUTA EM PAUTA: PERFORMANCES QUEER DE MADONNA E TERRITORIALI- DADES SEMIÓTICAS NO JORNALISMO DE CULTURA POP
}

CHRISTIAN GONZATTI UNIVERSIDADE DO VALE DO RIO DOS SINOS PORTO ALEGRE, RIO GRANDE DO SUL, BRASIL CHRISTIANGONZATTI@GMAIL.COM

FELIPE VIERO KOLINSKI MACHADO UNIVERSIDADE FEDERAL DE OURO PRETO OURO PRETO, MINAS GERAIS, BRASIL FELIPEVIERO@GMAIL.COM

RONALDO CESAR HENN UNIVERSIDADE DO VALE DO RIO DOS SINOS PORTO ALEGRE, RIO GRANDE DO SUL, BRASIL HENN.RONALDO@GMAIL.COM 


\section{A PUTA EM PAUTA: PERFORMANCES QUEER DE MADONNA E TER- RITORIALIDADES SEMIÓTICAS NO JORNALISMO DE CULTURA POP}

Resumo: Algumas performances de Madonna podem ser percebidas em uma dimensão queer. Através da análise de construção de sentidos em redes digitais, percebemos como notícias e matérias em veículos distintos podem acionar diferentes sentidos sobre a cantora, configurando territorialidades semióticas. Defendemos, por fim, novas miradas críticas dos processos jornalísticos que se voltam ao pop, assim como a necessidade de entender os vínculos de fãs com tais processualidades.

Palavras - chave: Jornalismo de cultura pop; Redes Digitais; Madonna; Queer.

\section{LA PUTA EN PAUTA: PERFORMANCES QUEER DE MADONNA Y TER- RITORIALIDADES SEMIÓTICAS EN EL PERIODISMO DE CULTURA POP}

Resumen: Algunas performances de Madonna pueden ser percibidas en una dimensión queer. A través del análisis de construcción de sentidos en redes digitales, percibimos como noticias y materias en vehículos distintos pueden accionar diferentes sentidos sobre la cantante, configurando territorialidades semióticas. Defendemos, por fin, nuevas miradas críticas de los procesos periodísticos que se vuelven al pop, así como la necesidad de entender los vínculos de fans con tales procesualidades.

Palabras - clave: Periodismo de Cultura Pop; Redes Digitales; Madonna; Queer.

\section{THE WHORE ON THE PRESS: MADONNA'S QUEER PERFORMANCE} AND SEMIOTIC TERRITORIALITIES AT POP CULTURE JOURNALISM Abstract: Some performances of Madonna can be perceived in a queer dimension. Through the analysis of the construction of senses in digital networks, we perceive how news and stories in different vehicles can trigger different senses about the singer, configuring semiotic territorialities. Lastly, we defend new critical views of journalistic processes that go back to pop, as well as the need to understand the ties of fans with such proceduralities. Key - words: Pop Culture Journalism; Digital Networks; Madonna; Queer. 


\section{INTRODUÇÃO}

Puta da Babilônia é uma personagem bíblica, mencionada nos capítulos 17 e 18 do Livro do Apocalipse. Vestindo as cores púrpura e escarlate, adornada com pedras preciosas e pérolas, assentada sobre as "grandes águas" em uma besta com sete cabeças e dez chifres, segurando um cálice de ouro com impurezas e "pecados da carne", ela seria o mal, as abominações e as práticas repugnantes, representando também a "Cidade" que reina sobre os reis da Terra. As "águas" em que ela estaria seriam povos, multidões, nações e línguas. Poderia tal profetização aproximar-se de Madonna, nos Estados Unidos e na cultura pop?

Fãs de diferentes produções mediáticas podem, dada a falta de materiais informativos sobre determinada celebridade, por exemplo, construir e organizar sites que trazem notícias, críticas e outros conteúdos sobre ela - buscando, inclusive, a formação jornalística para alavancar tais processualidades. Movimentos dessa ordem integram, entre outras dinâmicas, aquilo que pode ser compreendido como um jornalismo de cultura pop (AUTOR, 2017). A sexta turnê de Madonna, a Re-Ivention Tour, de 2004, foi catalisadora de acontecimentos sobre os quais muitos sites jornalísticos pop com vínculos de produção de fãs constituíram matérias, entre elas a especulação de que o nome da turnê seria The Whore Of Babylon. O Madonna Online desenvolveu, seguindo tal lógica, análises bíblicas para justificar o, posteriormente desmentido pela cantora, nome da tour - um exame detalhado que também é feito em videoclipes e trailers de filmes¹. Em movimento paralelo, sites de teorias da conspiração publicaram materiais que apontam os indícios na trajetória de Madonna possibilitadores de a consagrar como a "Puta da Babilônia"'.

Na década de 1920, caminhando pelas ruas de Paris, Walter Benjamin (2006) propôs uma reflexão sobre diferentes camadas de materiais que saltavam a sua percepção - ruas, lojas, exposições, iluminações, moda, tédio, entre outras sensibilidades percebidas e/ou sonhadas, que poderiam ser articuladas em diferentes e permeáveis constelações. No escopo das pes-

1 Texto disponível em: http://madonnaonline.com.br/2004/02/26/a-prostituta-da-babilonia/ Acesso em: novembro/2018.

2 Textos disponíveis em: http://nostradamuspredictions.org/nostradamus-madonna-prediction-madonna-whore-babylon; http://www.strangeconspiracies.com/2012/06/ madonna-original-whore-of-babylon-and.html Acesso em: novembro/2018. 
quisas realizadas pelo Laboratório de Investigação do Ciberacontecimento (LIC), o flâneur benjaminiano tem inspirado os exercícios metodológicos da Análise de Construção de Sentidos em Redes Digitais ${ }^{3}$ (HENN et al., 2017). Diferente da Análise de Redes Sociais (RECUERO et al, 2015), o método pressupõe um olhar para as microconexões e as complexidades de linguagem, sendo orientado pelas semióticas (PEIRCE, 2002; LOTMAN, 1986), visando a mapear significados, a elaborar constelações de sentidos e a desenvolver inferências sobre os processos através das lentes com as quais se está olhando o corpus. Seguindo tais proposições, para este artigo, desenvolveram-se arqueologias digitais que revelaram como questões que trazem em si signos queer performatizadas por Madonna ganham diferentes tessituras no jornalismo. Nesse processo, chegou-se não só à associação de Madonna com a "Puta da Babilônia", mas também a outros elementos que serão destacados aqui.

Para Adriana Amaral e Ariadne Mustafa (2015), a trajetória de Madonna foi analisada através de três qualificações: a virgem, a puta e a rainha. Partindo dessas complexas rotas célebres da cantora, nos questionamos, portanto: como performances específicas de Madonna, que trazem em si uma semioticidade puta, entendidas aqui em uma perspectiva queer, são operacionalizadas na interface entre jornalismo e cultura pop? De que maneiras territorialidades semióticas podem ser percebidas nesse contexto? E quais as possibilidades reflexivas e de exercício do jornalismo de cultura pop são sinalizadas em tal processo? Logo, a primeira parte do artigo trabalha com um recorte teórico-problematizador que sinaliza o nosso entendimento de performances queer, a segunda aborda a interface entre jornalismo e cultura pop e como territorialidades semióticas podem ser percebidas nesse processo para, então, desdobrarmos a análise. Desenvolvemos, também, um levantamento dos trabalhos ${ }^{4}$ que abordaram a relação entre Madonna, gênero, sexualidade, queer e/ou jornalismo visando a trazer contribuições ao campo e a contextualizar o nosso objeto.

3 Consideramos importante destacar que os aspectos advindos de Benjamin constituem uma camada de inspiração para o processo metodológico designado como Análise de Construção de Sentidos em Redes Digitais - para mais informações conceituais sobre essa metodologia consultar as obras citadas.

$4 \quad$ No Google Acadêmico e no Portal de Periódicos da Capes, buscaram-se pesquisas por meio das palavras - chave: Madonna e gênero; Madonna e queer; Madonna e sexualidade; Madonna e jornalismo e as interseccionalidades entre tais palavras. 


\section{O QUEER EM DIMENSÃO PERFORMÁTICA E PUTA}

Naquilo que tange a noção de performance, vale lembrar que há uma contradição quando o seu uso é feito em relação ao queer. Em tais estudos, a noção de performatividade vem sendo privilegiada e tomada como potente possibilidade de perceber como os discursos constituíram o sexo e, a partir de um sexo, o gênero - na medida em que, como consequência, sexo sempre foi gênero (BUTLER, 2003; 2014). Assim, o sexo, historicamente e culturalmente, foi administrado, sendo, desde o início uma categoria normativa, que impõe as formas de ser no mundo. Em outras palavras, "[...] é um constructo ideal que é forçosamente materializado através do tempo" (BUTLER, 1999, p. 111). Salih (2015), ao recuperar as discussões propostas por Butler no que se refere às diferenciações entre performatividade e performance, lembra que ao passo que a performance pressupõe um sujeito preexistente, a performatividade contesta a própria noção de sujeito.

Os estudos e ativismos queer, nessa perspectiva, empregam a noção de performatividade para entender como as sapatonas, as bichas, as transexuais, as travestis e outras identidades que enfrentam precariedades (BUTLER, 2015) podem, através de uma reapropriação da injúria (ERIBON, 2008), tomar para si o lugar de fala (PRECIADO, 2014). Portanto, se queer é um xingamento no contexto de língua inglesa, ele é também uma ofensa ressignificada e minada de outros sentidos. Ao mesmo tempo, entendemos, em concordância com Loureiro e Vieira (2015), que as regras de gênero podem ser performáticas e entendidas como fenômenos repetidos para simular uma ideia de naturalidade, mas, ao nos tornamos conscientes de algumas convenções sociais decorrentes dessa performatividade, que quase sempre é binária ao nosso olhar, dada à força das imposições de poder históricas e culturais, podemos performar o gênero normativo em alguns níveis. É o que fazem, por exemplo, algumas drag queens - o que foi motor para que Butler revisitasse algumas de suas contradições.

No que se refere ao contexto de seu desenvolvimento, pode-se dizer que as origens do que se concebe como teoria queer estariam ligadas à segunda onda feminista, ao movimento negro do sul dos Estados Unidos e, mais especificamente, à postura da população em geral frente aos homossexuais que, em um cenário de epidemia de AIDS e pelo medo da contaminação, eram percebidos como grupo abjeto cuja repulsa era recomendada e estimulada (queer nation). De um ponto de vista teórico e metodológico, ainda, 
ela seria herdeira do encontro dos Estudos Culturais norte-americanos com o Pós-Estruturalismo francês, tendo como aspecto importante a desconstrução das noção clássicas de sujeito e de identidade (MISKOLCl, 2015).

Teresa de Lauretis (1991), a quem se atribui o emprego inicial do termo queer, defenderá o seu uso como uma tentativa de perturbar a complacência da cômoda e bem estabelecida fórmula "estudos gays e lésbicos". A ideia seria, através desses trabalhos, aí alocados, estabelecer formas de resistência à homogeneização cultural e aos discursos dominantes de uma cultura heteronormativa. A Queer Theory, pois, traria imbricada a dupla ênfase de um trabalho conceitual e especulativo envolvido na produção de um discurso e, ao mesmo tempo, na desconstrução e crítica necessária de nossos próprios discursos e de nossos silenciamentos (DE LAURETIS, 1991). Os pensamentos e a ações queer seriam, como adjetiva Guacira Lopes Louro (2013), impertinentes, provocativas, perturbadoras, fascinantes, desrespeitosas, profanas, contestadoras.

Sendo o gênero constituído por relações de $\operatorname{poder}^{5}$ (SCOTT, 1995), nas quais o masculino estrutura-se como mais valorativo em relação ao feminino, propomos aqui a integração das lógicas do discurso que também agirão com força regulatória em relação a todas as mulheres. Puta e vadia, por exemplo, trazem em si as mesmas contradições e potências performativas de bicha, de viado e de sapatona. A Marcha das Vadias, entre outros ativismos feministas, tem seguido proposições de linguagem que são queer - a ressignificação de uma ofensa e o assumir o lugar de abjeção colocado por regimes regulatórios. Interpretamos, em tais conjunturas, que determinadas performances de Madonna podem ser lidas ou operacionalizadas por instâncias mediáticas como queer.

Kellner (2001) sugere que Madonna é capaz de inverter as relações e dominação no campo do gênero usando, inclusive, signos de opressão em sentidos de deboche e prazer libidinoso. O trabalho de Thrift (2003) aponta que "ser notícia" é um fator crucial para o sucesso econômico no contexto da cultura pop. Assim, apropriando-se de lógicas queer e performando ${ }^{6}$ uma

5 Scott (1995) ainda trabalhava com a distinção entre sexo e gênero borrada pelos estudos queer.

6 Destacamos a insuficiência da proposta em englobar, também, uma diferenciação crítico-reflexiva em torno das noções de performatividade e performance mais ampla, tendo em vista que tal esforço demandaria outro artigo. Compreendemos, ao mesmo tempo, que as noções de performance, por si só, geram um campo de estudos complexo 
"vagabunda", Madonna mobiliza contradições e tensões relacionadas aos feminismos e ao movimento LGBTQ, desenvolvendo performances que borram as categorias de homem e mulher e o binarismo de virgem e puta. Nessa conjuntura, os textos de Lima e Soares (LIMA, SOARES, 2014; LIMA, 2016; SOARES, LIMA, 2017) analisaram performances em diferentes shows de Madonna entendendo como questões políticas relacionadas ao gênero e aos seus diferentes marcadores de intersecção aparecem em tais atos performáticos, compreendendo que mesmo operando dentro de determinados pressupostos normativos de beleza hegemônica, a cantora é capaz de provocar desgosto, medo e ódio, pautando ideias relacionadas aos feminismos, ao queer e ao camp. Monteiro e Soares (2013) recuperam algumas polêmicas e discussões políticas que atravessaram o lançamento de videoclipes de Madonna, como a "fúria" causada nos setores mais conservadores da sociedade estadunidense com o lançamento de Like a Prayer, o que levou, inclusive, a perda de um contrato publicitário com a Pepsi. Lucena e Soares (2014) apontam como o a música e o videoclipe Express Yourself reforçam os lugares de poder do masculino e a fragilidade do feminino, assim como defendem a mirada crítica não-polarizadora em torno da cantora. Lucas de Carvalho (2016) desenvolve uma simetria entre a emergência de Madonna na década de 1980 e a gênese do queer. Monteiro e Silva (2018) analisam de maneira direta a representatividade e as contradições LGBTQs no clipe de Vogue, ressaltando o esvaziamento político de algumas identidades representadas no vídeo.

Há, portanto, uma mirada queer sobre as performances de Madonna no contexto acadêmico. Nosso foco, aqui, a partir desses lugares, passa a ser tentar perceber como a interface entre jornalismo e cultura pop vem semiotizando a "putaria" de Madonna. O próximo item, então, dedica-se a discutir tal interface para, na sequência, desenvolvermos um exercício de análise.

e multifacetado, como apontam o trabalho de Amaral, Soares e Polivanov (2018). Aqui estamos entendendo como performance, assim como faz Lima (2016) a partir de Carlson (2010), os agenciamentos de corpos e afetos que atravessam experiências mediadas por shows, estudos, programas de TV, rádios, sites de redes sociais, entrevistas. Acrescentamos que tais performances, em uma dimensão de signos, podem disparar produções de sentidos e acontecimentos (HENN et al., 2016). É nesse contexto que Madonna vem acontecendo. 


\section{JORNALISMO, CULTURA POP E TERRITORIALIDADES SEMIÓTICAS}

Em pesquisa Em pesquisa recente (AUTOR, 2017) defendeu-se o conceito de jornalismo de cultura pop`. Entre os movimentos metodológicos que sustentaram o processo, citamos a problematização do jornalismo cultural - e até que medida ele daria conta dos movimentos de cobertura informativa em torno da cultura pop; as aproximações e distanciamentos da noção de infotenimento; a mirada crítico-reflexiva sobre pesquisas que já traziam uma articulação entre o pop e o jornalismo; uma contextualização histórica de emergência da cobertura informativa sobre o pop - analisando a virtualidade de processos que resultariam na articulação entre a cultura pop e o jornalismo, como, por exemplo, a cobertura feita em revistas ${ }^{8}$; discussões conceituais sobre como a cultura digital potencializou os (ciber)acontecimentos que emergem do pop; e o mapeamento de veículos/plataformas que constituem tal jornalismo no contexto brasileiro visando criar categorias para refletir sobre essas complexidades. Trazemos uma discussão sobre esse último movimento articulando-o à noção de territorialidades semióticas.

Através de pesquisa exploratória, perceberam-se sete categorias de cobertura jornalística - a macrocategoria de cultura pop, que engloba todas as outras: música pop, celebridades, geek/nerd/otaku, cinema e séries, novelas e humor - e dois vínculos de produção - fãs e políticos-identitários. É importante destacar que um veículo pode estar presente em mais de uma categoria, na medida em que alguns cobrem noticiosamente a música pop e as celebridades, por exemplo. Ao mesmo tempo, instituições mais antigas e que passaram pelas instâncias de um jornalismo mais tradicional, apresentam sessões destinadas à cobertura da cultura pop em seus sites, muitas vezes organizadas por tags. É o caso de espaços como ZH Entretenimento, G1 Pop \& Arte, Veja Entretenimento, entre outros. Alguns constituem redes digitais específicas para tratar das temáticas pop, como o Veja Entretenimento, que possui perfis em sites de redes sociais para compartilhar notícias.

Entendendo que uma notícia configura-se como signo e dispara um pro-

$7 \quad$ Entende-se a cultura pop como os processos socioculturais, políticos, econômicos e os geográficos que envolvem o desenvolvimento de produtos mediáticos para o consumo engendrados por lógicas das indústrias culturais anglófilas-estadunidenses e que visam a conquista de mercados com alta visibilidade (VELASCO, 2010).

8 Temática que é aprofundada por Rossa (2018). 
cesso de semiose (PEIRCE, 2002) - ação, geração e propagação de outros signos - compreende-se que a distribuição de determinado veículo através de sites, blogs, sites de redes sociais distintos, como o Facebook, o Twitter e o Instagram, configuram semiosferas (LOTMAN,1996) específica através da qual acontecimentos pop configuram-se em semioses através de notícias e da ação dos públicos que consomem esses materiais (AUTOR, 2017). Isso implica na postulação de que há, por exemplo, no Papel Pop uma rede de sentidos diferente de outros veículos jornalísticos pop, como o Omelete. A noção de territorialidades semióticas, ao pressupor que territórios em rede são instituídos e atravessados por semioses complexas que constituem tensões, permeabilidades, fechamentos e semioticidades retrógradas e libertárias, pode ser aplicada para compreender como a cobertura da cultura pop tem, em algum nível, a semiosfera regulada pelas linguagens e temáticas de determinado veículo. Madonna, portanto, está incursa nesses processos jornalísticos que constroem realidades sobre nossas concepções de gênero (VEIGA DA SILVA, 2014).

Nos trabalhos de Monteiro e Soares (2013, 2014), são realizados apontamentos sobre o não reconhecimento do valor artístico de Madonna pelo jornalismo cultural, dada a maneira como as pautas são construídas através de subjetividades. Monteiro e Soares $(2013,2014)$ postulam uma especificidade no jornalismo cultural que circunscreva os produtos da cultura pop e a elaboração de críticas culturais que saiam de problemáticas do lugar comum e de hierarquias entre uma "alta cultura" e uma "baixa cultura" - que também são perpassadas por valores de masculinidade e feminilidade. Em Macedo e Silva (2015), embora não sejam especificadas metodologias e resultados de uma ordem empírica, é sublinhado o esvaziamento político e estético pela imprensa da obra de Madonna na cobertura da turnê The Girlie Show. É através de tais quadros que passamos para a análise da performances queer ${ }^{9}$ de Madonna na interface entre jornalismo, cultura pop e territorialidades semióticas.

9 Destacamos que como performances queer, estamos entendendo, em articulação com as lentes teóricas dos estudos de performance acionadas aqui - a maneira como Madonna é construída/constrói-se em diferentes enquadramentos mediáticos -, aquilo que remete historicamente a um espaço de limite performático demarcado em relação ao feminino. A ultrapassagem desse espaço qualifica mulheres como putas e vagabundas, remetendo, assim, as discussões que desenvolvemos sobre os estudos queer. 


\section{MARATONA SEXUAL (E JORNALÍSTICA) DE MADONNA}

Se notícias são signos que surgem através da ação de um interpretante sobre determinados acontecimentos, através delas também se constituem semiosferas e territorialidades semióticas. Passamos, em consequência, a flanar, cartografando em diferentes temporalidades e contextos das redes digitais, materiais jornalísticos em torno de Madonna. Através da busca por palavras-chave em navegadores ocultos ${ }^{10}$ - visando a diminuir a influência dos algoritmos - trazemos algumas semioticidades constelacionais e subjetivas que buscam dar conta das problemáticas do artigo.

A primeira delas é um vídeo ${ }^{11}$ publicado no YouTube sobre uma reportagem do Jornal Nacional em outubro de 1992 que abordava o lançamento do livro Sex ${ }^{12}$. Cid Moreira, apresentador do programa, faz uma introdução detendo-se sobre o valor de divulgação do que o programa chama de "pacote erótico de Madonna” - aproximadamente 65 milhões de dólares, o que equivalia a mais de 500 bilhões de cruzeiros. Depois são intercaladas imagens do videoclipe ${ }^{13}$ com a tradução dublada de qualificações de quatro homens e uma mulher sobre o trabalho da performer: "ela é um máximo", "vou ver se consigo de graça”, "ela foi um pouquinho longe demais", "ela é louca", "é ótima”, respectivamente. A voz do jornalista Paulo Henrique Amorin anuncia o lançamento do "livro Erotica e o disco Sex", apresenta fãs - "fregueses" - usando as "fantasias das personagens" do livro. Posteriormente, o programa detém-se nos valores econômico em torno da publicidade do livro que retrata as fantasias sexuais da cantora, no qual, segundo o telejornal, "Madonna faz tudo o que é possível imaginar e muito mais". Depois citam que Clark Gable teria causado, em 1934, uma queda nas vendas de camisetas nos Estados Unidos ao aparecer sem uma por baixo da camisa em um filme, uma crise, em 1955, causada por combinações de Marilyn Monroe no Japão e encerram a reportagem perguntando o que iria acontecer

10 Utilizamos o modo oculto do Google Chrome.

11 Vídeo disponível em: https://www.youtube.com/watch?v=NR5_ilQ_5-E\&t=7s. Acesso em: novembro/2018.

12 Sex é um livro escrito por Madonna, com fotografias tiradas por Steven Meisel e quadros de filmes feitos por Fabien Baron. O livro foi editado por Glenn O'Brien e lançado em 21 de outubro de 1992 pela Warner Books, Maverick Books e Callaway Books.

13 Vídeo disponível em: https://www.youtube.com/watch?v=WyhdvRWEWRw. Acesso em: novembro/2018. 
com a "maratona sexual de Madonna?".

Ao entrar em processo de recirculação, a pauta em torno de Madonna ganha outras possibilidades mediáticas. Nos comentários acionados pela reportagem, ganham destaque o deboche e a crítica em relação a desinformação prestada pelo jornalismo ao confundir os nomes do livro e do álbum, um "flop" na perspectiva de um ator social em rede. Madonna é apontada como uma "lenda viva", a "Vai Malandra de 25 anos atrás" - um paralelo feito em relação à cantora brasileira Anitta - e a causadora de situações nas quais o "patriarcado chora". Os vinte comentários vão de 10 anos - o material foi publicado em 25 de abril de 2007 por um perfil pessoal - até meados de 2018. Um deles faz o seguinte apontamento: "A economia do país deveria estar muito bem obrigado, Madonna no Jornal Nacional". O que reitera a distinção entre hard news e soft news através de valores generificados em um sistema binário (VEIGA DA SILVA, 2014): relevante-irrelevante, razão-emoção, masculino-feminino, força-fraqueza, por exemplo.

Visando a refletir sobre as seções em jornais mais tradicionais, trouxemos a notícia que mais aparecia em buscas no Google referente às palavras "Madonna" e "sexo" articuladas. Elegemos a publicação da GaúchaZH (antes Zero Hora), um veículo da RBS, filiada da Rede Globo, para elaborarmos inferências: "Madonna promete sexo oral a quem votar em Hillary Clinton"1". Abaixo do título em destaque, com uma fonte bold, um lead discreto: "Cantora deu a declaração, em tom de brincadeira, durante uma apresentação da humorista Amy Schumer, em Nova York". A matéria destaca a campanha de Madonna para Hillary, a data da votação e contextualiza o momento da "brincadeira" - que foi reverberada em muitos portais jornalísticos. No Facebook ${ }^{15}$, o título foi alterado para "Madonna esquenta a campanha eleitoral americana", com a seguinte legenda: "Madonna prometeu presente 'quente' aos eleitores que votarem em Hillary Clinton". Uma estratégia que visava a mobilizar o clique no site e que, ao mesmo, reitera o masculino como universal e como foco da "brincadeira" sexual de Madonna - em uma perspectiva heterossexual.

Os comentários do site aparecem totalmente descontextualizados, na

14 Texto disponível em: https://gauchazh.clicrbs.com.br/cultura-e-lazer/noticia/2016/10/madonna-promete-sexo-oral-a-quem-votar-em-hillary-clinton-7860509.html. Acesso em: novembro/2018.

15 Postagem disponível em: https://www.facebook.com/gauchazh/ posts/10150807847354956. Acesso em: novembro/2018. 
medida que se referem a outras notícias. Ao mesmo tempo que cogitamos ser alguma falha na programação, observamos que alguns perfis sinalizavam o mesmo erro em outras notícias com conteúdos polêmicos. Questiona-se, então, se o movimento seria uma estratégia para evitar a materialização de comentários odiosos na rede do veículo. Em relação ao Facebook, Madonna aparecerá como vetor de disputas políticas entre Trump e Hilary, com direito a publicação de informações falsas (a de que a vitória da candidata levaria a uma guerra, por exemplo), sendo qualificada como "uma artista pervertida e doente que apoia candidatos de esquerda", e recebendo respostas machistas e idadistas em relação à brincadeira do sexo oral: "velha desse jeito?”, "ninguém quer um boquete dessa véia louca, deixa pro Jesus luz!", "esta bruxa vai fazer um sexo oral com o bill”, "um pedaço de pelanca esticada”, "parece a freira do The Conjuring 2", “com dentadura ou sem?”.

No que se refere especificamente a um exercício de jornalismo de cultura pop, selecionamos materiais do Papel Pop - que estaria na macrocategoria sinalizada anteriormente por abordar múltiplos temas. A primeira matéria que trazemos é a notícia sobre o lançamento de um novo videoclipe de Madonna: "Madonna volta para o sexo, o pecado e a pegação no clipe de 'Girl Gone Wild'!16". Utilizando GIFs de momentos tórridos do vídeo - como um modelo que balança o volume em sua cueca - o texto da matéria qualifica o material como o mais "gay do ano", no qual Madonna dança com as "bees" de salto alto, apontando também referências a outros videoclipes da carreira da artista, como Vogue e Erotica, e a outras músicas que, na percepção do jornalista Phelipe Cruz, poderiam ter sido um single do álbum MDNA, fechando o texto com a frase "There's only one queen and that's Madonna, bitch!". No Facebook, a notícia foi compartilhada com a legenda: “Madonna só no pecado e na pegação no clipe de 'Girl Gone Wild’!'”. . Apenas no site de rede social houve comentários ${ }^{18}$ que vão celebrar o retorno de Madonna - "será que ela ouviu nossas orações e voltou a ser puta?”, "essa sim é a Madonna”, "um dos clipes mais lindos dos últimos anos", "é genial a forma como ela provoca a Igreja, a religião!” - e desenvolver disputas de fãs, prioritariamen-

16 Texto disponível em: http://www.papelpop.com/2012/03/madonna-volta-para-o-sexo-o-pecado-e-a-pegacao-no-clipe-de-girl-gone-wild/ . Acesso em: novembro/2018.

17 Postagem disponível em: https://www.facebook.com/papelpop/ posts/196701417106900. Acesso em: novembro/2018.

18 O Papel Pop alterou o sistema de comentários da plataforma Disquus para o Facebook, o que fez com que comentários antigos fossem perdidos. 
te entre Lady Gaga e Madonna - "copiou a Gaga”, "copiou a Gaga? Antes da Gaga nascer Madonna já tinha feito isso, pf né”. "Gaga who?", "Alejandro”.

Objetivando trazer um recorte do processo de semiose de uma notícia na mesma territorialidade em outro contexto temporal, selecionamos a matéria "Estamos aplaudindo o discurso incrível de Madonna ao aceitar prêmio de Mulher do Ano"19", do Papel Pop. O texto cita o prêmio da Billboard conferido à celebridade e destaca os principais pontos do seu discurso de agradecimento trazendo trechos da fala. Citamos e destacamos alguns trechos do discurso na tradução feita pelo site.

Se você é uma garota, você tem que jogar o jogo. Você tem permissão para ser bonita, fofa e sexy. Mas não pareça muito esperta. Não haja como você tivesse uma opinião que vá contra o status quo. Você pode ser objetificada pelos homens e pode se vestir como uma puta, mas não assuma e se orgulhe da puta em você. E não, eu repito, não compartilhe suas próprias fantasias sexuais com o mundo. Seja o que homens querem que você seja, e mais importante, seja alguém com quem as mulheres se sintam confortáveis por você estar perto de outros homens. E por fim, não enveIheça. Porque envelhecer é um pecado. Você vai ser criticada e humilhada e definitivamente não tocará nas rádios[...] Eu me lembro de ser a manchete de cada jornal e revista. Tudo que eu lia sobre mim era ruim. Eu era chamada de vagabunda e de bruxa. Uma das manchetes me comparava ao demônio (COVRE, 2016, s/p).

No Facebook ${ }^{20}$, a notícia foi compartilhada com a legenda: "Só podemos dizer: Rainha MESMO! <3". No processo semiótico desencadeado pela matéria, aparecem seis das sete constelações de sentidos percebidas em pesquisa anterior (AUTOR, 2017). As linguagens desenvolvidas por grupos LGBTQs (“pisa menos Madonna, eu te imploro!"; "lacradora”; memes da cantora $)^{21}$, as transviadices, que falam de sexo, de putaria e subvertem lógi-

19 Texto disponível em: http://www.papelpop.com/2016/12/estamos-aplaudindo-o-discurso-incrivel-de-madonna-ao-aceitar-premio-de-mulher-do-ano/. Acesso em: novembro/2018.

20 Postagem disponível em: https://www.facebook.com/papelpop/ posts/932539996778241. Acesso em: novembro/2018.

21 Os comentários entre parênteses não foram os únicos de cada constelação de sen- 
cas heterossexuais ("dona do meu cool" - com uma foto de Nick Minaj com a bunda empinada; montagens com o beijo de Madonna e Britney Spears), feminismos ("gays e essa eterna mania de colocar as mulheres umas contra as outras [...]"), que se configura como um comentário extenso criticando comentários que colocavam uma disputa entre divas como foco da conversação; "eu sou uma feminista má arrepiei todinha", destacando a importância representacional de Madonna para mulheres e LGBTQs ("não existe dinheiro, não existe coroa que pague tudo que você fez pra um mundo mais livre"; "se hj muitas rebolam em cima dos palcos, ou fazem suas performances sem serem crucificados, foi porque Queen $M$ fez antes e apanhou por elas!"), colocações que reforçam preconceitos ("faz bacanal com os Dançarinos, usa drogas, tá tudo errado nessa porra. Puta que pariu") - que apareceram com pouca intensidade - e enfrentamentos ativistas e problematizações mais críticas ("rainha sim. mas a Billboard só tem eleito mulheres brancas"; "Bela, Recatada e do Lar"22").

O nosso flanar orientado pela análise de construção de sentidos em redes digitais constituiu uma percepção da performance puta, e, portanto, queer, de Madonna que extrapola a materialidade textual colocada no artigo. Citamos, entre tantos casos, a coluna crítica da GaúchaZH sobre o discurso da Billboard, do jornalista Paulo Germano "Que feminismo é esse, Madonna?23"; blogs antifeministas que trazem uma mirada conservadora sobre as performances queer de Madonna24; os acontecimentos relacionados à campanha de Hilary, como a vez em que Madonna mandou Trump "chupar um pau"25" e disse que poderiam "explodir a casa branca ${ }^{26}$ ", o que fez com o que o polí-

tido.

22 https://catracalivre.com.br/entretenimento/tumblr-bela-recatada-e-do-lar-reune-memes-incriveis-em-resposta-materia-da-revista-veja/. Acesso em: novembro/2018.

23 Texto disponível em: https://www.facebook.com/gauchazh/ posts/10150852418384956. Acesso em: novembro/2018.

24 Texto disponível em: https://mulherescontraofeminismo.wordpress. com/2016/10/26/a-feminista-madonna-oferece-sexo-oral-para-quem-votar-para-hillary-clinton/. Acesso em: novembro/2018.

25 Texto disponível em: http://www.papelpop.com/2017/01/madonna-manda-donald-trump-chupar-um-pau-em-show-na-womens-march/. Acesso em: novembro/2018.

26 Texto disponível em: http://www.papelpop.com/2017/01/madonna-explica-frase-sobre-explodir-casa-branca-em-marcha/. Acesso em: novembro/2018. 
tico a chamasse de nojenta ${ }^{27}$ e com o que o seu conselheiro a ameaçasse de prisão por terrorismo ${ }^{28}$; simetrias acontecimentais entre Madonna e outros casos que utilizaram simbologias cristãs, como a trans cruficada na parada LGBTQ ${ }^{29}$; além de plataformas que desenvolvem uma curadoria informativa e arqueológica em torno da cantora, como a Madonna Literal, que recupera ${ }^{30}$ uma reportagem do Jornal da Globo sobre os 25 anos do documentário $\mathrm{Na}$ Cama com Madonna que a categoriza como "moradora do imaginário masculino"; ou ainda a página do Facebook Poser de Madonna ${ }^{31}$, que compartiIha e traduz seus vídeos para o português - como uma entrevista na qual ela diz que foi ameaçada de morte na Rússia por defender os direitos LGBTQ ${ }^{32}$.

Através do processo analítico de cartografar múltiplas e distintas territorialidades semióticas, trazemos, então, algumas considerações sobre os questionamentos que nortearam a pesquisa.

\section{CONSIDERAÇÕES FINAIS}

As performances de Madonna que se aproximam de uma lógica queer têm a sua potência semiótica ressignificada através do enquadramento em diferentes contextos jornalísticos. Operacionalizar a cultura pop como notícia é uma tarefa que ganha intencionalidades diversas. Em um contexto mais tradicional-histórico, como os percebidos, por exemplo, no Jornal Nacional e no Jornal da Globo, as semioticidades em torno de Madonna são construídas em uma perspectiva higienizadora, não sendo utilizadas palavras "sujas". Trata-se de um modelo de cobertura masculina, focada em aspectos econômicos e quantitativos, nas quais alguns equívocos revelam catalisações do

27 Texto disponível em: http://www.papelpop.com/2017/01/ela-e-nojenta-diz-donald-trump-sobre-madonna/. Acesso em: novembro/2018.

28 Postagem disponível em: https://www.facebook.com/portalpopline/photos |a.10150220957829341.339347.312641429340/10155255242249341/?type=3\&permPage=1. Acesso em: novembro/2018.

29 Postagem disponível em: https://www.facebook.com/g1/posts/975517532500332. Acesso em: novembro/2018.

30 Postagem disponível em: https://www.facebook.com/MadonnaLiteral/videos/1343362585709183/. Acesso em: novembro/2018.

31 Postagem disponível em: https://www.facebook.com/madonnaposer/. Acesso em: novembro/2018.

32 Postagem disponível em: https://www.facebook.com/madonnaposer/videos/1037952246288609/. Acesso em: novembro/2018. 
presente em que fãs desenvolvem a cobertura jornalística das produções mediáticas e das celebridades. Ressaltamos a importância de se refletir sobre a percebida articulação entre a vivência fã e o jornalismo de cultura pop, capaz de mobilizar, inclusive, a formação jornalística em fãs, como no caso do Papel Pop. Nesse contexto de cobertura, Madonna é capturada em perspectiva menos “limpa”, com expressões próximas dos seus públicos no contexto brasileiro, embora não exista com frequência uma análise estética ou crítico-reflexiva das suas obras, prevalecendo uma perspectiva enaltecedora. As notícias, no entanto, são ressemantizadas e passam a inaugurar diferentes sentidos, configurando outras territorialidades semióticas.

Nesses territórios, então, semioticidades de diferentes ordens ganham materializações através linguagens revelam outros aspectos em torno das performances de Madonna. A possibilidade de recircular conteúdos jornalísticos através das plataformas da internet permite que tais produtos sejam acessados em uma outra dimensão crítica, apontando, por exemplo, erros e aspectos obliterados em determinadas reportagens. A construção de sentidos e a possibilidade de serem instituídas territorialidades semióticas através de redes digitais é um processo dinâmico, em constante transformação, no qual podem ser apreendidas diferentes percepções sobre múltiplos objetos, incluindo os da cultura pop. Territorialidades distintas são configuradas através de jornalismos e linguagens selecionadas para a construção das notícias. Em GaúchazH, por exemplo, são acionados comentários odiosos sobre Madonna através da apropriação noticiosa da sua brincadeira política de cunho-sexual: uma postura puta que não estaria adequada a sua idade. Em uma matéria crítica sobre o feminismo de Madonna, aparecem sentidos de fechamento em relação ao diálogo com o veículo e muitas oposições a um homem escrever sobre feminismo - o que foi potencializado pelo teor do texto, que tenta colocar um tom vitimista no discurso feito para o prêmio da Billboard. No Papel Pop, em 2012, prevalecia na rede digital do veículo uma incessante disputa de fãs sobre as suas divas, já em um contexto mais contemporâneo, tal disputa ainda aparece, mas dá espaço a comentários mais críticos e que abordam questões não mencionadas no texto da matéria, assim como a uma performance política que celebra o "ser puta" de Madonna - o que se aproxima do queer. Ainda em outros contextos, como o da Poser de Madonna, podem ser notadas discussões configuradoras de territorialidades semióticas na qual predominam a construção de afetos e sensibilidades sobre a trajetória da cantora. 
A construção de notícias e de materiais críticos sobre Madonna poderia ir além da intencionalidade inauguradora de polêmicas e disputas de sentidos para atrair cliques e/ou visibilidade. Cabe questionar como a subjetividade das/dos comunicadores em relação à cultura pop vem sendo construída em suas formações acadêmicas - pensando inclusive em relatos de conflitos sobre entender tais objetos como dignos de pesquisas. Há uma possibilidade de formação sobre a cultura pop que saia das lógicas binárias e do espectro ódio-amor? Bessa (2016, p. 31) reflete que "[...] o apelo da crítica queer é justamente o de sensibilizar nosso olhar para enfrentar novos campos de batalha”. O jornalismo poderia valer-se de tais aspectos e operacionalizar a cultura pop em uma dimensão pedagógica-transformadora, desenvolvendo diálogos com as territorialidades semióticas que o atravessam, visibilizando e conversando com o olhar estético que muitos trabalhos acadêmicos apresentam. As matérias sobre Madonna poderiam, assim, construir novas percepções sobre as "putarias", afervorando "corações rebeldes" e revolucionários.

\section{REFERÊNCIAS}

AMARAL, Adriana; SOARES, Thiago; POLIVANOV, Beatriz. Disputas sobre performance nos estudos de Comunicação: desafios teóricos, derivas metodológicas. Intercom - RBCC, São Paulo, v.41, n.1, p.63-79, jan./abr. 2018.

AMARAL, Adriana; MUSTAFA, Ariadne. Informação Verbal. 2015.

AUTOR.

BENJAMIN, Walter. Passagens. Belo Horizonte: Editora UFMG; São Paulo: Imprensa Oficial do Estado de SP, 2006.

BESSA, Karla. A Teoria Queer e os desafios às molduras do olhar. Cult, São Paulo: Editora Bregantini, $\mathrm{n}^{\circ}$ 6, ano 19, janeiro 2016.

BUTLER, Judith. Corpos que pesam: sobre os limites discursivos do "sexo". In.: LOURO, Guacira Lopes. 0 corpo educado: pedagogias da sexualidade. Belo Horizonte, Autêntica, 1999.

BUTLER, Judith. Problemas de Gênero: feminismo e subversão da identidade. Tradução de Renato Aguiar. Rio de Janeiro, 2003: Civilização Brasileira.

BUTLER, Judith. Quadros de guerra: quando a vida é passível de luto. Rio de Janeiro: Civilização Brasileira, 2015.

CARLSON, Marvin. Performance: uma introdução crítica. Belo Horizonte: Editora UFMG, 2010.

CARVALHO, Vinícius Lucas de. Madonna queer: teoria queer e representatividade LGBT na biografia de cinquenta anos do maior ídolo da música pop. Atas do V Congresso Interna- 
CADERNOS DE COMUNICAÇÃO

UNIVERSIDADE FEDERAL DE SANTA MARIA

cional em Estudos Culturais, Universidade de Aveiro, Portugal, 2016.

COVRE, Giulia. Estamos aplaudindo o discurso incrível de Madonna ao aceitar prêmio de Mulher do Ano. 2016. Disponível em: http://www.papelpop.com/2016/12/estamos-aplaudindo-o-discurso-incrivel-de-madonna-ao-aceitar-premio-de-mulher-do-ano/ Acesso em: novembro/2018.

DE LAURETIS, Teresa. Queer theory: Lesbian and gay sexualities. Indiana University Press, 1991.

ERIBON, Didier. Reflexões sobre a questão gay. Rio de Janeiro: Companhia de Freud, 2008.

HENN, Ronaldo; GONZATTI, Christian; ESMITIZ, Francielle. Pussy Made Of Steel: os sentidos inaugurados por um cartaz da Women's March na página Supergirl Brasil. Revista Fronteiras, 19(3):401-414 setembro/dezembro 2017.

HENN, Ronaldo; GONZATTI, Christian; KOLINSKI MACHADO, Felipe Viero. Jordan lives for the applause: perfomances de si como propulsoras de ciberacontecimentos. In: Encontro Anual da Compós, 25., 2016, Goiânia: UFG, 2016.

KELLNER, Douglas. A cultura da mídia- estudos culturais: identidade e política entre o moderno e o pós-moderno. Bauru, SP: EDUSC, 2001.

LIMA, Mariana Lins; SOARES, Thiago. “Open your Heart to Me”: Ritualização Midiática e Sacralização na Performance de Madonna. XVI Congresso de Ciências da Comunicação na Região Nordeste, Intercom, João Pessoa, PB, 15 a 17/05/2014.

LIMA, Mariana Lins. Pop don't preach: a construção de narrativas políticas na música pop. XVIII Congresso de Ciências da Comunicação na Região Nordeste, Intercom - Caruaru - PE - 07 a 09/07/2016.

LOTMAN, Yuri. La semiosfera: semiótica de la cultura y del texto. Madri: Catedra, 1996.

LOUREIRO, Gabriela; VIEIRA, Helena. Transgênero. Galileu- Gênero, tudo o que você sabe está errado. São Paulo: Editora Globo, n²291, nov. 2015.

LOURO, Guacira Lopes. Um corpo estranho - ensaios sobre sexualidade e teoria queer. 2 ed. Belo Horizonte: Autêntica Editora, 2013.

LUCAS DE CARVALHO, Vinícius. Madonna queer: teoria queer e representatividade LGBT na biografia de cinquenta anos do maior ídolo da música pop. Atas do V Congresso Internacional em Estudos Culturais, Universidade de Aveiro, Portugal, 2016.

LUCENA, Victória Junqueria Ayres; SOARES, Thiago. “Express Yourself”: Binarismo de Gênero na Desconstrução de Madonna. $18^{\circ}$ Redor, Universidade Federal Rural de Pernambuco, Recife, 24 a 27 de novembro de 2014.

MACEDO, André Souza Nascimento; TEODORO DA SILVA, Ana Cristina. Gênero e Erotismo na Cobertura Midiática de Madonna: "The Girlie Show". XXXVIII Congresso Brasileiro de Ciências da Comunicação, Intercom, - Rio de Janeiro, 2015.

MISKOLCI, Richard. Teoria Queer: um aprendizado pelas diferenças. Belo Horizonte: Autêntica Editora, 2015. 
MONTEIRO, Gabriel Holanda; SILVA, Naia Rodrigues da. “Come on, Vogue!": Madonna e a construção da identidade LGBT através da representação simbólica na música pop. Ano XIV, n. 1., Temática, Janeiro/2018.

MONTEIRO, Maria Helena; SOARES, Thiago. Museu de Grandes Novidades: Crítica, Agendamento e Valor sobre a Obra de Madonna no Jornalismo Cultural. Intercom, XVI Congresso de Ciências da Comunicação na Região Nordeste - João Pessoa, 2014.

MONTEIRO, Maria Helena; SOARES, Thiago."You Must Be My Lucky Star": A Relevância da cantora Madonna na Gestão de Carreiras da Música Pop. XV Congresso de Ciências da Comunicação na Região Nordeste, Intercom, 2013.

PEIRCE, Charles Sanders. The Collected Papers of Charles Sanders Peirce. Past Masters, CD-ROM. EUA, InteLex Corporation, 2002.

PRECIADO, Beatriz. Testo Yonqui: sexo, drogas e biopolítica. Madrid: Espasa-Calpe, 2008. PRECIADO, Paul Beatriz. Manifesto Contrassexual. São Paulo: n-1 edições, 2014.

RECUERO, Raquel; BASTOS, Marco; ZAGO, Gabriela. Análise de redes para mídia social. Porto Alegre: Sulina, 2015.

ROSSA, Letícia. “Brasil, Mostra a Tua Cara”: valores identitários na cultura pop de Rolling Stone. Dissertação de mestrado, Unisinos, São Leopoldo, 2018.

SALIH, Sara. Judith Butler e a Teoria Queer. $1^{\mathrm{a}}$ ed, $3^{\mathrm{a}}$ reimp. Belo Horizonte: Autêntica Editora, 2015.

SCOTT, Joan. Gênero: uma categoria útil de análise histórica. Educação e Realidade, 20 (2), jul/dez, 1995.

SILVA, Marcia Veiga da. Masculino, o gênero do jornalismo: modos de produção das notícias. Florianópolis: Insular, 2014.

SOARES, Thiago; LIMA, Mariana Lins. Políticas de gênero nas performances de Madonna. Vozes \& Diálogo, Itajaí, v. 16, n. 02, jul./dez. 2017.

THRIFT, Samantha C. Appropriate the Stereotype: Cultural Appropriations and the Queer, Lesbian, and Madonna and Martha Stewart. Thridts Space, a journal of feminist theory \& culture. Março, 2003.

VELASCO, Tiago. Pop: em busca de um conceito. Animus - Revista interamericana de comunicação midiática, v.17, jan-junho, 2010. 


\section{Christian Gonzatti}

Doutorando e Mestre em Ciências da Comunicação pela UNISINOS.

E-mail: christiangonzatti@gmail.com

\section{Felipe Viero Kolinski Machado}

Professor Adjunto do Departamento de Jornaslismo da UFOP. Doutor em Ciências da Comunicação pela UNISINOS. E-mail: felipeviero@gmail.com

\section{Ronaldo Cesar Henn}

Professor do Programa de Pós-Graduação em Ciências da Comunicação da UNISINOS. Coordenador do Laboratório de Investigação do Ciberacontecimento.

E-mail: henn.ronaldo@gmail.com 